\title{
A avaliaçáo e o currículo no Ensino Superior: pensando a formaçáo e a prática docente
}

\author{
Kelry Alves Gonçalves* \\ Jackeline Império Soares**
}

\section{Resumo}

Este artigo contempla avaliação e currículo no nível superior de educação, especificamente nos cursos de formação inicial do professor. Usou-se de pesquisa bibliográfica com o objetivo principal de elucidar se o Ensino Superior, mesmo apregoando uma avaliação e um currículo na concepção crítica de educação, ainda realiza estes dois movimentos na tendência tradicional. As questôes orientadoras são: "Da mesma forma que o aluno aprende a avaliar durante o curso de licenciatura, assim avaliará como professor?" e "Até que ponto a teoria 'pregada' sobre o currículo durante a formação se 'cumpre' na prática?”. Considerou-se então, a partir do ideário pedagógico crítico, que os professores, durante toda a graduação, estudam sobre um currículo emancipador, construído nas diferenças culturais e uma avaliação dialética que acompanha o desenvolvimento do estudante; contudo, são avaliados em forma de exame e considerados como sacerdotes de um currículo fixo e intocável. Assim, eles tendem a reproduzir as mesmas metodologias às quais foram submetidos e a aceitarem o rumo neoliberal imposto ao currículo. Entretanto, a proposta é que haja mudança, vontade para fazer o novo, em não seguir as regras estatisticamente impostas por outras instâncias e outros poderes que, em geral, nem conhecem o ato de ensinar e aprender dentro da sala de aula.

Palavras-chave: avaliação, currículo, Ensino Superior, professor.

\section{Assessment and the curriculum in higher education: thinking out formation and educational practice}

\begin{abstract}
That article analyzes assessment and curriculum in the context of higher education, and more specifically in courses for the initial formation of teachers. A bibliographical research was used to see if higher education, while claiming to use assessment curriculum according to a critical conception of education, still carry out these two activities in the traditional mold. The guiding questions are: "Will the teacher assess in the same way that $s /$ he learned to assess as an undergraduate?" and "To what extent is the theory about curriculum, presented during formation, put into practice?” Throughout the whole undergraduate period teachers

* Faculdade de Educação, Universidade Federal de Goiás (FE/UFG). E-mail: kelryag@gmail.com

** Faculdade de Educação, Universidade Federal de Goiás (FE/UFG). E-mail: jackelineufg@gmail.com
\end{abstract}


study liberating curricula from a critical pedagogical stance, based on cultural differences and on dialectic assessment which accompany the student's development. They are assessed, however, in an exam format within a fixed untouchable curriculum. Thus, they tend to reproduce the same methodologies as those to which they were submitted and accept the neoliberal character imposed on the curriculum. However, there is a proposal for change, a willingness to introduce the new, and not follow the rules statistically imposed by other spheres and powers which usually know nothing about the teaching and learning that happens in the classroom.

Keywords: assessment, curriculum, higher education, teacher.

\section{Introdução}

Embora muito se tenha discutido nos últimos anos sobre a avaliação, é fato que a confusão entre avaliar e examinar continua dentro e fora do contexto educacional. Isso porque o ato de avaliar possui uma nuance com $o$ ato de examinar. A constante confusáo entre esses dois atos se deve por fazerem parte de um mundo social permeado pela historicidade e pela cultura. É fato que a todo instante o ser humano examina e também avalia o que lhe rodeia, procurando respostas a diversas questóes que surgem nas suas interaçóes.

Enquanto o exame basicamente seleciona, separa, classifica, a avaliação inclui um julgamento de valor sobre as açóes e os resultados; por isso, esses dois atos também estão situados além dos muros da escola. Contudo, a avaliação não ocupa o pódio "de melhor do que" o exame; na verdade, cada um desempenha seu papel em contextos específicos nos quais sua utilização é proveitosa. O equívoco está em elaborar e utilizar um instrumento avaliativo ou examinatório para um determinado contexto que ele não consegue contemplar; essa confusão gera consequências graves.

Intrínseco à avaliação está o currículo, um artefato social e cultural presente na educação. $\mathrm{O}$ currículo traz os objetivos da educação escolar e propóe um plano de açáo para o cumprimento desses tais objetivos. De modo geral, é aquilo que a sociedade espera que seja selecionado da cultura produzida por ela e ensinado/aprendido durante a formaçáo dos alunos. Assim, ele é o apontador das questôes "o quê?", "como?" e "quando?" ensinar e avaliar. Em especial, o currículo representa tudo o que o aluno precisa aprender no meio social e escolar. Ele representa os vários tipos de aprendizagens. 
Com diversas formas de manifestação, o currículo demonstra que o ensino e aprendizagem depende de que a escola e o corpo docente confrontem a cultura elaborada presente no currículo formal com as situaçóes existentes de fato no contexto, na realidade, na cultura do educando, ou seja, com a identidade formada em virtude das relaçooes vividas na família, na comunidade e obtida pela mídia. Nesse espaço está a formação do professor, sua subjetividade e a sua prática, pois o docente está entre a formulação do currículo e o seu cumprimento com os alunos.

Por isso, sobre a temática da formação de professores, este artigo tem como objetivo geral abordar a avaliação e o currículo no Ensino Superior, especialmente na formação de professores, para responder às questôes: da mesma forma que o aluno aprende a avaliar durante o curso de licenciatura, assim avaliará como professor? Até que ponto a teoria "pregada" sobre o currículo durante a formação se "cumpre" na prática? Para tal reflexão, usou-se de revisão bibliográfica nos escritos que versavam sobre avaliação educacional, currículo, Ensino Superior e formação de professores.

Este artigo partirá do assunto avaliação no Ensino Superior, para depois tocar no tema currículo, e por fim haverá a articulação entre eles, deixando claro que, embora estes dois campos sejam relatados, em primeiro momento, separadamente, um não tem razão de existência sem o outro. Também discorrerá sobre a prática avaliativa na formação de professores com a intenção de mostrar o ideal e o real, assim como os possíveis resultados. Como segundo ponto, abordará o currículo, esclarecendo seus aspectos essenciais e a ligação entre este, a ideologia, a cultura e o poder; em conseguinte, o currículo e a formação de professores para também confrontar o ideal e o real. Por fim, abordará a percepção e proposta sobre a avaliação e o currículo e as relaçôes, no Ensino Superior, com a atual formação e presente e/ou futura prática docente.

\section{A avaliação e o Ensino Superior: suas intrínsecas relaçóes}

A avaliação possui um funcionamento sócio-histórico constituindo diversas facetas conforme a sociedade, o contexto e a cultura. Na educação, ela depende do recinto institucional escolar e universitário quanto às tendências sociais e políticas, que por sua vez são ligadas aos interesses dos governos, da economia, da mídia, da população e, especialmente, das instâncias de poder. Por isso, esta prática é dinâmica (DIAS SOBRINHO, 2002). 
Luckesi (2011) esclarece que o verbo avaliar é associado a outros como investigar, conhecer, agir, pesquisar, educar. É necessário perceber a realidade, as concepçóes prévias, a bagagem cultural de quem se pretende educar, suas diferentes leituras do mundo; ter consciência dessa realidade atrelada à concepção de educação que concerne à epistemologia, ética, metodologia e ao instrumento a ser usado. Então, a avaliação não acarreta valor, não é absoluta nem definitiva, mas uma atividade em processo para o professor observar a aprendizagem do aluno e para intervir nos problemas notados. A avaliação é, entấo, o acompanhamento dos estudos feitos que visa a conquistar os resultados desejados. Em linhas gerais, ela se realiza em três passos: descrever, qualificar e intervir na realidade. Ela é processo, percurso, e não apenas o produto final.

Mas, a avaliação possui uma herança histórica que é examinatória e junto a ela existe uma resistência à mudança do ato de examinar para o de avaliar. Confirmando estas ideias, Luckesi (2011) faz duas constataçóes: 1) a escola pratica mais exames que avaliação; 2) há resistência a transitar do ato de examinar para o de avaliar. Dentro da escola, a avaliação tem caráter de classificação, seletividade, autoritarismo e poder, porque a educação está ligada, dentro da visão neoliberal, à eficiência do ensino. Como é difícil avaliar, esse processo não muda conforme o nível educacional. Os mesmos conflitos, as mesmas confusôes e resistências à mudança de examinar para avaliar na Educação Básica também ocorrem no Ensino Superior.

No Ensino Superior, há a tradição de ensino, pesquisa e extensão. Mas, Assis (2008, p. 38) acentua que

[...] o processo de expansão da educação superior no Brasil, ocorrido na década de 1990, vem transformando os conceitos até então vigentes de democratizaçáo do acesso ao ensino superior e dos processos de avaliação sistêmica das IES (Instituiçóes de Educação Superior) públicas e privadas no Brasil.

Ainda sobre este assunto, Mendes (2006, p. 29) afirma:

A avaliação não é levada a sério no ensino superior; que não é muito diferente da educação básica, quando se trata de centralização do poder e controle por meio dos professores, e que o instrumento mais usado para avaliar é a prova. [...] os estudos sobre formação de professores não têm considerado a questáo da avaliaçáo educacional como integrante de seu processo de formação. 
O que ocorre entre a relação avaliação e Ensino Superior é a teoria separada da prática. Primeiro, porque a educação superior está progressivamente sendo descaracterizada no processo de "democratização" das IES, aumentando seu número de vagas para se adequar ao mundo globalizado e ao mercado de trabalho que tem se tornado cada vez mais flexível e exigente (ASSIS, 2008). Segundo, porque a avaliação no nível superior ainda é uma área de trabalho com pouco reconhecimento e baixa produção. Terceiro, porque ainda que professores e estudantes reconheçam a definição, o papel e as consequências na ação avaliativa, "poucos dentre eles se dispóem a parar para refletir, analisar, estudar e se preparar de maneira específica para enfrentar os problemas envolvidos na avaliação do processo de ensino e aprendizagem" (LUDKE e SALLES, 1997, p. 169 apud MENDES, 2006, p. 24).

\section{$\mathrm{O}$ ato de avaliar na formação de professores}

Se a produção sobre avaliação no Ensino Superior é reduzida, quando focada nos curso de formação de professores, esse número tende a diminuir. Quanto às licenciaturas, Mendes (2006) considera que estão a serviço das sociedades capitalistas que impóem ideias e tendências, comprometendo a formaçáo do professor. $\mathrm{Na}$ visão das políticas educacionais, a formação de professores é marcada pelo aligeiramento e pela fragmentação; é voltada para a qualidade da instrução e do conteúdo, centralizando nas competências e habilidades; e espera-se um técnico-profissional no saber fazer.

Cardoso (1996 apud MENDES, 2006) constata que os modelos de avaliação na formação de professores permitem quantificar resultados e classificar os alunos, pois os professores acreditam que assim estáo garantindo a cientificidade do processo avaliativo. Dessa forma, o professor formador de outros professores continua com uma prática que valoriza apenas o exame, confirmando assim a prática examinatória na prática do aluno como professor.

De fato, as questôes pedagógicas ocupam lugar insignificante na formação inicial desses professores e na sua formação continuada. Há uma preocupação quase exclusiva com o domínio do conteúdo da disciplina específica ou da área de pesquisa. Parece ser consenso que a avaliação deve ser um domínio do fazer docente, mas os cursos não têm contemplado a formaçáo pedagógica dos professores no contexto do ensino superior. Desse modo, a avaliaçáo não tem sido um dos temas 
de estudo teórico/prático para formar os professores. (MENDES, 2006, p. 26)

Todavia, enquanto por um lado os professores agem como reprodutores e "repassadores" de conteúdos que são provados diante de uma prova, por outro, o aluno se submete a este fazer pedagógico por náo ter a dimensão do seu compromisso social como acadêmico e acomoda-se diante do "pouco" que recebe (ELICKER, 2002, p. 88 apud MENDES, 2006, p. 30 e 31). Os estudantes se tornam profissionais docentes sem entender qual a função da avaliação, quais as suas finalidades, sem se perguntarem para quais sujeitos elas servem. Por isso, o professor precisa ter a consciência do seu comprometimento com a aprendizagem do aluno, mas isso não retira do estudante a sua responsabilidade em buscar a sua própria mudança, a dos atos metodológicos aos quais está sujeito e da instituição. A formação é um viés de mão dupla; como educador-educando e educando-educador, a avaliação precisa ser um todo e não o tudo para promover a aprendizagem e o crescimento de ambos. Aliado à questáo da avaliação, está o currículo, assunto que será tratado a seguir.

\section{Currículo: cultura, ideologia e poder}

A palavra currículo assim como avaliação é usada com diferentes sentidos e definiçôes. De forma mais abrangente, o currículo tem dois frequentes usos: um para designar as matérias que constam em um curso, o conteúdo de um assunto; outro como o programa que define uma instituição, como a concretização das intençóes e orientaçóes expressadas no Projeto-Político-Pedagógico (PPP).

Há muitas definições de currículo: conjunto de disciplinas, resultados de aprendizagem pretendidos, experiências que devem ser proporcionadas aos estudantes, princípios orientadores da prática, seleção e organização da cultura. (LIBÂNEO; OLIVEIRA; TOSCHI, 2005, p. 362)

Dessa forma, o planejamento depende também da concepção de currículo que se tem. Sacristán (1995 apud VASCONCELLOS, 1999, p. 230) exemplifica muito bem essa afirmação ao dizer que se

Por currículo se entendeu de forma dominante o compêndio de conteúdos, planejá-lo é fazer um esboço ordenado do que se deveria 
transmitir ou aprender sequenciado adequadamente [...] Se por currículo se entendesse um conjunto de objetivos para serem alcançados junto aos alunos, o plano é a estrutura e ordenação precisa dos mesmos para obtê-los por meio de certos procedimentos concretos. Finalmente, se por currículo oculto, o plano deve contemplar náo apenas a atividade de ensino dos professores, mas também todas as condiçóes do ambiente de aprendizagem graças às quais se produzem esses efeitos: relaçóes sociais na aula e na escola, uso de textos escolares, efeitos derivados das práticas da avaliação etc.

Sendo assim, ao se pensar em um conjunto de atividades que abarque o processo educacional está se pensando na elaboraçáo e realização (o que inclui a avaliação) de um programa que sintetize e confirme tais experiências pedagógicas a serem contempladas para o ensino e a aprendizagem. $\mathrm{O}$ currículo é a síntese das crenças, dos conhecimentos, valores, costumes, hábitos; de elementos culturais que contemplam uma proposta educativa por e para diferentes grupos sociais que são diversos e contraditórios em seus interesses. O currículo está além da transmissáo de conteúdos a um sujeito passivo com a comprovação através de exames; ele reflete a natureza do conhecimento e a do conhecedor assim como a metodologia para a aquisição de tal conhecimento. Assim, ele permite conhecer o processo da aprendizagem (VASCONCELLOS, 1999, p. 99).

A definição seguinte sintetiza bem a noção que nos parece adequada: [Currículo é] o conjunto dos conteúdos cognitivos e simbólicos (saberes, competências, representaçôes, tendências, valores) transmitidos (de modo explícito ou implícito) nas práticas pedagógicas e nas situaçōes de escolarização, isto é, tudo aquilo a que poderíamos chamar de dimensão cognitiva e cultural da educação escolar. (LIBÂNEO; OLIVEIRA; TOSCHI, 2005, p. 362; grifo do autor)

Isso significa que o currículo de forma alguma pode ser considerado como "um elemento inocente e neutro de transmissão do conhecimento cultural” (TENREIRO; BRANDALISE, 2002, p. 131). De fato, ele é um campo influenciado pelos valores sociais, políticos e históricos. Por isso, quando se assume a concepçáo de currículo e a concepçáo de avaliaçáo, assume-se a própria concepção social e política; tomando partido por uma determinada proposta pedagógica. Torres (1995, p. 16 apud TENREIRO; BRANDALISE, 2002, p. 131) diz que: 
Toda concepção curricular implica sempre uma determinada proposta pedagógica (uma proposta sobre o que e como se deve ensinar; aprender ou avaliar; o papel dos diferentes sujeitos em tudo isso, seus modos de se relacionar; etc.) e reflete uma determinada concepção, não só do educativo, mas do social, do político, do cultural etc.

Assim, considerando esse conjunto de experiências sobre um fundamento lógico, global, planejado e desenvolvido, vale conhecer as diferentes expressóes do currículo: a) Currículo formal: indicado por propostas pedagógicas em documentos oficiais e em regimentos escolares. b) Currículo real ou em ação: aquilo que de fato ocorre na escola; a interpretação que acontece quando professores e alunos unem as experiências de cada um ao que foi expresso no currículo formal. c) Currículo oculto: aquilo que não está explicitado, mas tem uma força na formação para direcionar as mudanças educacionais (TENREIRO; BRANDALISE, 2002, p. 134).

É notável que, ao pensar e realizar o currículo, seleciona-se um universo de possibilidade cultural, o que torna o currículo uma prática de significados expressos entre conflitos e relaçóes de poder que produzem identidades sociais. A cultura é o terreno da educação. Por isso, Arroyo (2011) afirma que o currículo é um território de disputas, porque ele forma identidades. Porém, sabendo que há o currículo formal, o real e o oculto, consequentemente, há uma formação ideal demonstrada nas propostas do currículo e uma formação real que acontece na prática educacional. Assim, falar em currículo é falar em cultura, mas também em ideologia e poder.

A esse respeito, Moreira e Silva (1995, p. 23) afirmam que a ideologia "está relacionada às divisóes que organizam a sociedade e às relaçóes de poder que sustentam essas divisóes". Os autores esclarecem que não se trata de caracterizar a ideologia com ideias falsas ou verdadeiras; é preciso considerar o fato de que essas ideias veiculadas por uma determinada classe são interessadas em transmitir uma visão de mundo social do grupo hegemônico. Portanto, o relevante é saber a quem tal ideologia beneficia.

O currículo está no centro das relaçôes de poder. "É a visão de que a educação e o currículo estão profundamente implicados em relaçóes de poder que dá à teorização educacional crítica seu caráter fundamentalmente político" (MOREIRA; SILVA, 1995, p. 28). O poder se manifesta nas linhas que dividem os diferentes grupos sociais; nas relaçóes sociais em que certos grupos ou indivíduos estão submetidos à vontade de outros. Para os autores, "essas forças vão desde o poder dos grupos e classes dominantes 
corporificado no Estado quanto nos inúmeros atos cotidianos nas escolas e salas de aula" (1995, p. 30).

\section{O currículo no Ensino Superior: o ser professor}

De acordo com as afirmaçôes sobre a relação entre o Ensino Superior e a avaliação, pode-se dizer que este nível sempre foi visto como conservador e com currículos pouco flexíveis. De acordo com Cuchiaro e Carizio (2005, p. 2),

Considerando nosso enfoque, o ensino superior, os currículos dos cursos de graduaçáo muitas vezes são elaborados de forma unilateral, não existindo a participação dos alunos na elaboraçáo de seus conteúdos e, muitas vezes, nem ao menos dos professores. Currículos de Instituiçôes renomadas são frequentemente tidos como base para a elaboração dos currículos de instituiçốes menores, estas últimas não levam em consideraçấo os aspectos sociais e culturais de sua regiáo e muitas vezes não sabem sequer de que forma ocorreu a formulação do currículo da Instituição que lhe serviu como base.

Convém lembrar que, como assegura Arroyo (2011, p. 13),

$\mathrm{Na}$ construção espacial do sistema escolar, o currículo é o núcleo e o espaço central mais estruturante da função da escola. Por causa disso, é o território mais cercado, mais normatizado. Mas também o mais politizado, inovado, ressignificado.

Compartilhando as afirmações desses dois autores, é possível esclarecer que as IES passaram, assim como a educação básica, por diferentes tendências (higienista, militarista, pedagogicista, tecnicista), norteadas conforme os interesses políticos de cada momento histórico. A educação passou por distintos decretos e leis que foram criados, estabelecidos, reformados até chegarem às leis, diretrizes, aos planos, projetos etc. nacionais, estaduais e municipais vigentes atualmente como também reformulados conforme interesses coletivos e/ou individuais. Todavia, da necessidade humana de alterar o mundo, os quatro vetores - globalização, neoliberalismo, novas tecnologias, mundo da informação -, segundo Sacristán (2008), propiciam diretamente as mudanças na educação; por isso, mudanças no currículo.

$\mathrm{Na}$ formação histórica do Brasil, certos conhecimentos foram marginalizados, decretados inexistentes, ficando fora da história intelectual e 
cultural da humanidade, no conhecimento socialmente produzido, acumulado e repassado dentro das escolas. Mas, os possuidores destes conhecimentos aumentam sua quantidade no acesso às escolas, criando uma densa linha entre os conteúdos valorizados no currículo e exigidos nas avaliaçóes e os conhecimentos e culturas presentes na sala de aula.

Para esclarecer essa discussáo, Arroyo (2011) considera que o campo do conhecimento é mais dinâmico, complexo e disputado. Sendo assim, as relações sociais e políticas de dominação e subordinação disputam a produçấo e a apropriação do conhecimento. É fato que dentro desse território em disputa, o professor tem um papel central nessa ação, pois ele realiza, no dia a dia, a construção das interaçôes no ambiente escolar. Há uma estreita relação entre o currículo e a prática docente.

As políticas curriculares do que ensinar e como ensinar, do que avaliar, exigir dos professores e dos alunos nas provas escolares e nacionais ou estaduais têm agido como um marco conformador e controlador do trabalho e das identidades profissionais. (ARROYO, 2011, p. 30)

Vale lembrar que a identidade é o que constitui o sujeito e é construída e reconstruída por meio da socialização do subjetivo e do coletivo. A identidade, conforme Pimenta e Lima (2010), é formada através do trabalho. Arroyo (2011) tece uma crítica à grande lacuna entre a formação e a prática docente. Ele diz que o ser professor é ditado bem mais pela atuação deste profissional do que pela formação; são exigidas funçôes e práticas que a formação deixou carente. Somos obrigados a aprender o que nem sempre aprendemos nos cursos de formaçáo, de licenciatura ou de pedagogia para sermos educadores(as).

O currículo é tomado como sagrado e o professor é considerado o sacerdote responsável em mantê-lo e perpetuá-lo intocável. Sobre a avaliação, os graduandos e atuais ou futuros professores se formam sem apreender qual o sentido e a função de utilizar um instrumento para acompanhar a aprendizagem do aluno e acabam, dessa forma, confundindo o ato de avaliar com o de examinar, submetendo o seu trabalho, o seu salário, a sua carreira e os seus alunos às condiçōes dos resultados matemáticos e estatísticos das aferiçôes do governo; dessa mesma maneira ocorre com o currículo.

Nos cursos de licenciatura, os licenciados acompanharam o dinamismo intelectual de suas áreas e aprenderam a prestigiá-las. Entretanto, como 
professores de ensino fundamental ou médio, tiveram de aprender que os conteúdos sistematizados nos currículos e nas disciplinas perdem esse caráter dinâmico inerente a sua produção e passam a ser sistematizados, ordenados e sequenciados em uma transposição que exige uma ordem estática, rígida a ser seguida, respeitada com uma fidelidade sagrada, ritualizada. (ARROYO, 2011, p. 45)

De forma alguma o conteúdo é o "bicho-papão" do insucesso escolar, assim como a avaliação também não pode assumir esse papel, pois a existência destes e a forma como são constituídos dependem da organização curricular que é pensada teoricamente como articuladora do macro e microconhecimento considerado universal e daquele que é local, mas na maioria das vezes o currículo valoriza apenas os conteúdos conhecidos como sagrados, rígidos e desarticulados. Assim, os conselhos, os regimentos, as diretrizes e normas são afirmadas para obrigarem os docentes a respeitarem a carga horária, as hierarquias, as sequências, as linearidades. Ocorre um contraste entre a educaçáo básica e a educação superior quanto à liberdade de pesquisa, à produção e ao ensino, consequentemente, escala-se os professores por grau de importância conforme o nível educacional lecionado e os títulos que cada um possuiu.

\section{Consideraçốes e discussóes finais}

A ação pedagógica está entre diversos questionamentos e indagações, pois a globalização, o multiculturalismo, os rápidos avanços e desenvolvimentos econômicos e técnicos a todo instante põem a escola, os professores e os alunos perante novas exigências. A instituição educativa não está fixada e rígida no tempo e no espaço; ela precisa cumprir o propósito da sua existência, articular-se aos problemas, saberes, avanços e questionamentos do mundo globalizado. Há um valor social e cultural na educação que se expressa no currículo e na avaliação. Exatamente por isso, a escola não pode ficar alheia a todo esse constante movimento; ela deve expressar, através do currículo e da avaliação, as intençóes educativas do planejamento e seu desenvolvimento para obter resultados que não se encerram em si mesmos, mas que, articulados, desenvolvem o ensino e a aprendizagem.

A palavra formação possui uma dimensão que remete à complexidade do ser humano e da educação. Por isso, não é mais possível conceber na formação de professores uma avaliação que seja alienante. A avaliação é 
emancipatória para superar as fragmentações. A perversão que existe no fato de, na avaliação, nota valer mais do que a aprendizagem gera a falta de ligação com a pesquisa e a formação inicial dos professores. Avaliar exige pesquisa e sem essa relação, as teorias são desarticuladas das práticas; os professores conhecem a avaliação na teoria, mas não a conduzem em sua prática docente.

É necessário caminhar rumo à superação das formas da educação tradicional e introduzir a dimensão política no trabalho pedagógico do professor. Isso é formar professores para agir como sujeitos e não como meros executores do processo educativo ou das políticas educacionais. Os professores, por serem educadores, precisam estar conscientes da sua responsabilidade de atores principais para desencadear novos processos avaliativos para a educação, pois, em geral, o aluno de licenciatura tende a reproduzir na prática o que aprendeu/aprende em sua formação.

Assim, é proposta a avaliação em sua natureza pura: enfoque crítico, dialético, diagnóstico e formativo, pois o papel da escola não é o de selecionar e classificar, mas de diagnosticar, acompanhar e auxiliar o educando a se desenvolver durante a aprendizagem. Isso sem deixar de considerar as implicaçóes políticas e sociais que envolvem a temática avaliação e formação de professores. E claro, para se discutir a avaliação em sua complexa atuação, é necessário pensar também o currículo e, por conseguinte, a cultura.

Este artigo retorna, então, à questão proposta em sua introdução: "Até que ponto a teoria "pregada" sobre o currículo durante a formação se "cumpre" na prática?". Segundo a pesquisa bibliográfica sobre o currículo e a avaliação, sobretudo na formaçáo e prática do professor, os textos apontam para o fato de que se aprende um ideal a cumprir, mas exige-se um real para realizar. Arroyo (2011) deixa claro esse assunto ao afirmar que o currículo tem mais um caráter de controlador do que de disputa. Muito se apregoa sobre a extrema necessidade e relevância de um currículo e uma avaliação que sejam emancipadores, críticos, sociais, libertadores; contudo, a exigência da sociedade, do Estado e especialmente da globalização na pessoa do mercado não permite que tais ambiçóes sejam levadas à frente, pois contrastam com as aspiraçóes do capitalismo, do neoliberalismo vigente.

Enfim, acredita-se que ainda é tempo de mudança. Não há tempo para lamentar e aceitar as desigualdades do sistema capitalista e aceitar que o professor assuma o papel de "coitado", "sem oportunidades"; um passo importante é aceitar a necessidade de mudança e ter coragem para realizá- 
la mesmo que ela dependa de instâncias superiores. A luta pode ser curta ou longa, mas jamais um educador pode deixar de defender um currículo elaborado conforme a realidade local e mundial, que dê oportunidade para uma construção plural pelos sujeitos que conhecem a escola, a sala de aula, o movimento do ensinar e aprender, a comunidade na qual a instituiçáo escolar está inserida.

Aí está a beleza do ato de ser educador e educadora: conseguir juntar em um ato o rigor da ciência e o respeito pelo senso comum; ser consciente de que é necessário construir e não simplesmente aceitar tudo o que é dado, ou imposto. Educar não permite receitas, mas exige educadores comprometidos em ser mais.

\section{Referências}

ARROYO, Miguel G. Curriculo, território em disputa. Petrópolis, RJ: Vozes, 2011. p. 9-52.

ASSIS, Lúcia Maria de. Avaliação institucional e prática docente na educação superior: tensóes, mediaçóes e impactos. 244 p. Tese (Doutorado) - Programa de Pós-Graduação em Educação, Faculdade de Educação, Universidade Federal de Goiás, Goiânia, 2008. p. 44-64.

CUCHIARO, André Luiz; CARIZIO, Walkiria Graick. Ensino superior, currículo e formação profissional. Revista Fafibe On-line. São Paulo: Faculdades Integradas FAFIBE, ano I, n. 1, jul. 2005.

DIAS SOBRINHO, José. Campo e caminhos da avaliação superior no Brasil. In: FREITAS, Luiz Carlos de. (Org.). Avaliação: construindo o campo e a crítica. Florianópolis, SC: Insular Editora, 2002.

LIBÂNEO, José Carlos; OLIVEIRA, João Ferreira de; TOSCHI, Mirza Seabra. As áreas de atuação da organização e da gestáo escolar para melhor aprendizagem dos alunos. In: . Educação escolar: políticas, estrutura e organização. São Paulo: Cortez, 2005. (Coleção Docência em Formação).

LUCKESI, Cipriano Carlos. Avaliação da aprendizagem: componente do ato pedagógico. 1. ed. São Paulo: Cortez, 2011. p. 149-294.

MENDES, Olenir Maria. Formação de professores e avaliação educacional: o que aprendem os estudantes das licenciaturas durante sua formação. 214 p. 
Tese (Doutorado) - Programa de Pós-Graduação em Educação, Faculdade de Educação, Universidade de São Paulo, São Paulo, 2006. p. 15-45.

MOREIRA, Antonio Flávio; SILVA, Tomaz Tadeu (Org.). Currículo, cultura e sociedade. Tradução de Maria Aparecida Baptista. 2. ed. revista. São Paulo: Cortez, 1995.

PIMENTA, Selma Garrido; LIMA, Maria Socorro Lucena (Coord.). Estágio e construção da identidade profissional docente. In: . Estágio e docência. 5. ed. São Paulo: Cortez, 2010. (Coleção Docência em Formação. Série Saberes Pedagógicos).

SACRISTÁN, José Gimeno. O significado e a função da educação na sociedade e na cultura globalizadas. In: GARCIA, Regina Leite; MOREIRA, Antonio Flavio Barbosa (Org.). Currículo na contemporaneidade: incertezas e desafios. Tradução de Silvana Cobucci Leite; Beth Honorato; Dinah de Abreu Azevedo. 3. ed. São Paulo: Cortez, 2008.

TENREIRO, Maria Odete Vieria; BRANDALISE, Mary Angela Teixeira. Avaliação da aprendizagem e currículo: algumas reflexões. Olhar de professor. Ponta Grossa: Universidade Estadual de Ponta Grossa: ano/v. 5, n. 1, p. 129-139, 2002.

VASCONCELLOS, Celso dos Santos. Planejamentos: Projeto de EnsinoAprendizagem e Projeto Político-Pedagógico. 5. ed.. Sáo Paulo: Libertad, 1999. (Cadernos Pedagógicos do Libertad, v. 1).

Recebido em: 31 maio 2012

Aceito em: 15 set. 2012 